\title{
The study on the effects of different soda slag treatments on chlorine ion content
}

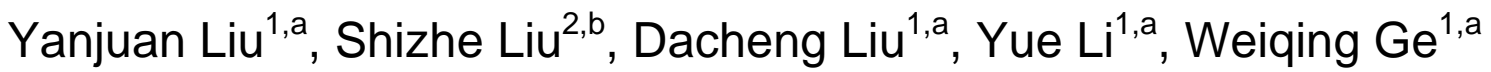

1 Department of Environmental \& Chemical Engineering, Tangshan College, Tangshan, 063000

China

2 College of Chemical Engineering, China University of Petroleum, Qingdao, 266580

China

aemail: juan1809@163.com

Keywords: Ammonia-soda process; Soda slag; Chlorine ion; Coal ash; Sodium silicate

\begin{abstract}
Soda slag, produced as the solid waste from the ammonia-soda process, was treated by heating, adding additives and other methods. It was found that the chlorine ion content changed with the treatment of heating or adding additives. Heating treatment showed little effect on the decrease of chlorine ion content. The addition of additives, especially coal ash, had an effect on reducing the chlorine ion content in soda slag. Moreover, with the addition of coal ash, the chlorine ion content decreased gradually. The chlorine ion content reached $0.078 \mathrm{~g} / \mathrm{g}(7.8 \%)$ at the amount of coal ash $10 \%$.
\end{abstract}

\section{Introduction}

Large amounts of soda slag are produced as the solid waste from the ammonia-soda process. Deposition of piles of soda slag has a negative impact on the environment and occupies lots of lands. Thus comprehensive advantage should be taken from the view of economy and environment. Up to now, researchers have done a lot of research and found applications of soda slag in concrete, cement and other construction materials [1-5]. However, with much chlorine ions contained in soda slag, its application is quite limited. Therefore, it is important to reduce the dissociative chlorine ions in soda slag. In this paper, treatments of heating and adding additives are employed for the sake of the decrease of chlorine ions content.

\section{Experimental}

\subsection{Materials}

Major raw materials used in the experiment are soda slag, coal ash, sodium silicate and so on.

The soda slag is obtained from a soda-ash factory using ammonia-soda process in Tangshan. The chemical composition of soda slag is given in Tab.1.

Tab.1 Chemical composition of the soda slag

\begin{tabular}{cccc}
\hline Composition & Content(\%) & Composition & Content (\%) \\
\hline $\mathrm{CaSO}_{4}$ & 45.6 & $\mathrm{Al}_{2} \mathrm{O}_{3}$ & 3.0 \\
$\mathrm{CaCO}_{3}$ & 3.9 & $\mathrm{Fe}_{2} \mathrm{O}_{3}$ & 0.7 \\
$\mathrm{CaCl}_{2}$ & 10.5 & $\mathrm{SiO}_{2}$ & 7.8 \\
$\mathrm{CaO}$ & 10.3 & $\mathrm{Mg}(\mathrm{OH})_{2}$ & 9.0 \\
$\mathrm{NaCl}$ & 2.7 & $\mathrm{H}_{2} \mathrm{O}$ & 5.3 \\
\hline
\end{tabular}

Coal ash is obtained from a power plant in Tangshan. Tab.2 shows the chemical composition of coal ash. 
Tab.2 Chemical composition of the coal ash

\begin{tabular}{cccc}
\hline Composition & Content (\%) & Composition & Content(\%) \\
\hline $\mathrm{SiO}_{2}$ & 50.9 & $\mathrm{SO}_{3}$ & 0.8 \\
$\mathrm{Al}_{2} \mathrm{O}_{3}$ & 28.1 & $\mathrm{Na}_{2} \mathrm{O}$ & 1.8 \\
$\mathrm{Fe}_{2} \mathrm{O}_{3}$ & 6.2 & $\mathrm{~K}_{2} \mathrm{O}$ & 0.6 \\
$\mathrm{CaO}$ & 3.7 & Igloss & 6.8 \\
$\mathrm{MgO}$ & 1.2 & & \\
\hline
\end{tabular}

\subsection{Instruments}

Instruments used in the experiment are listed in Tab. 3.

Tab. 3 Experiment instruments

\begin{tabular}{ccc}
\hline Instrument & $\begin{array}{c}\text { Specification and } \\
\text { Model }\end{array}$ & Manufacturer \\
\hline $\begin{array}{c}\text { Electrothermal blowing } \\
\text { drying oven }\end{array}$ & $101-1$ & $\begin{array}{c}\text { Tianjin Experimental Instrument Plant } \\
\text { Nanjing Nanda Tianzun Electronics } \\
\text { Call mill }\end{array}$ \\
$\begin{array}{c}\text { ND-4L Ltd. } \\
\text { Rapid chlorine ion content } \\
\text { analyzer }\end{array}$ & SX2-4-10 & $\begin{array}{c}\text { Tianjin Zhonghuan Experimental } \\
\text { Furnace Co., Ltd. }\end{array}$ \\
\hline
\end{tabular}

\subsection{Methods}

The desired amounts of dried soda slag (or dried soda slag after treatment) were dissolved in distilled water and vigorously stirred for some time. The rapid chlorine ion content analyzer was used to determine the chlorine ion content in the sample.

Methods for the treatment of soda slag were described as follows: heat treatment by directly heating the sample; treatments with different kinds of additives in various amounts.

\section{Results and discussion}

\subsection{Effect of stirring time on the chlorine ion content}

$10 \mathrm{~g}$ soda slag was dissolved in $200 \mathrm{~mL}$ distilled water. The resulting suspension or solution was stirred using a magnetic stirring apparatus for some time. Chlorine ion content in the sample was determined with the rapid chlorine ion content analyzer.

A series of samples treated with different prepared to study the effect of stirring time on the chlorine ion content. The stirring time was 1 h, 2 h, 4 h, 8 h and up to 24 h, separately. The results were illustrated in Tab.4.

Tab. 4 Effect of stirring time on the chlorine ion content

\begin{tabular}{cc}
\hline Stirring time $(\mathrm{h})$ & Chlorine ion content in the sample $(\mathrm{g} / \mathrm{g})$ \\
\hline 1 & 0.183 \\
2 & 0.192 \\
4 & 0.210 \\
8 & 0.214 \\
12 & 0.215 \\
16 & 0.215 \\
20 & 0.218 \\
24 & 0.220 \\
\hline
\end{tabular}


As shown in Tab. 4, the chlorine ion content in the samples increased with the extension of stirring time. However, the growth of the chlorine ion content slowed down gradually and changed little after $8 \mathrm{~h}$. It could be concluded that stirring had an effect on the release of chlorine ion in soda slag, and the process of releasing could be almost complete in $8 \mathrm{~h}$. Therefore, the preferable stirring time for the measurement of chlorine ion content was $8 \mathrm{~h}$.

\subsection{Effect of heating temperature on the chlorine ion content}

The soda slag samples were heated at $500{ }^{\circ} \mathrm{C}, 700{ }^{\circ} \mathrm{C}, 900{ }^{\circ} \mathrm{C}, 1100{ }^{\circ} \mathrm{C}$ and $1300{ }^{\circ} \mathrm{C}$ for $2 \mathrm{~h}$, respectively. After cooling to ambient temperature, the samples were ground and sieved to more than 200 mesh for later use.

$10 \mathrm{~g}$ sample was dissolved in $200 \mathrm{~mL}$ distilled water and the solution was under vigorous stirring for $8 \mathrm{~h}$. Then the chlorine ion content was measured (as shown in Tab. 5).

Tab.5 Effect of heating temperature on the chlorine ion content

\begin{tabular}{cc}
\hline $\begin{array}{c}\text { Heating temperature } \\
\left({ }^{\circ} \mathrm{C}\right)\end{array}$ & $\begin{array}{c}\text { Chlorine ion content in the } \\
\text { sample }(\mathrm{g} / \mathrm{g})\end{array}$ \\
\hline 25 & 0.214 \\
500 & 0.125 \\
700 & 0.098 \\
900 & 0.136 \\
1100 & 0.162 \\
1300 & 0.227 \\
\hline
\end{tabular}

From Table 5 we found that at the beginning of the increase of heating temperature the chlorine ion content decreased gradually. Some of the chlorine ions volatilized with the increasing temperature, resulting in the decrease in chlorine ion content. While above $900{ }^{\circ} \mathrm{C}$, the chlorine ion content rose instead, which was attributed to the decomposition of carbonates in soda slag. Therefore, single heat treatment was unqualified for reducing the chlorine ion content in soda slag.

\subsection{Effect of amount of coal ash on the chlorine ion content}

The soda slag and coal ash were dried, ground and sieved to more than 200 mesh. A series of samples were obtained by adding different amounts of coal ash into soda slag.

The addition of coal ash was based on the amount of soda slag. $2 \mathrm{~g}, 4 \mathrm{~g}, 6 \mathrm{~g}$ and $10 \mathrm{~g}$ coal ash were mixed with $100 \mathrm{~g}$ soda slag, respectively, to prepare the samples of $2 \%, 4 \%, 6 \%$ and $10 \%$ content, as defined. After fully mixed, certain amounts of samples (each containing $10 \mathrm{~g}$ soda slag) were dissolved in $200 \mathrm{~mL}$ distilled water and stirred for $8 \mathrm{~h}$. The chlorine ion contents were measured and results were reported in Tab. 6.

Tab.6 Effect of amount of coal ash on the chlorine ion content

\begin{tabular}{cc}
\hline Amount of coal ash (\%) & Chlorine ion content in the sample (g/g) \\
\hline 2 & 0.192 \\
4 & 0.125 \\
6 & 0.094 \\
8 & 0.082 \\
10 & 0.078 \\
\hline
\end{tabular}

Tab.6 showed that the chlorine ion content declined with the addition of coal ash. With base in soda slag, activation of the coal ash took place, to form gel. As a result, the fixation of gel with the chlorine ions led to the decline of the dissociative chlorine ion content. 


\subsection{Effect of amount of sodium silicate on the chlorine ion content}

The soda slag was dried, ground and sieved to more than 200 mesh. Add different amounts of sodium silicate into the soda slag and a series of samples were prepared.

The addition of sodium silicate was based on the amount of soda slag, which was defined the same as in 3.3. The effect of the amount of sodium silicate added on the chlorine ion content was presented in Tab.7.

Tab. 7 Effect of amount of sodium silicate on the chlorine ion content

\begin{tabular}{cc}
\hline Amount of sodium silicate(\%) & Chlorine ion content in the sample (g/g) \\
\hline 2 & 0.210 \\
4 & 0.202 \\
6 & 0.190 \\
8 & 0.185 \\
10 & 0.172 \\
\hline
\end{tabular}

The addition of sodium silicate had an effect of constraint on the chlorine ion in soda slag (shown in Tab.7). Increasing the amount of sodium silicate, the chlorine ion content detected in soda slag decreased slightly.

\section{Conclusions}

The measurement of the chlorine ion content was related to the stirring time of soda slag. Longer stirring time led to more leached chlorine ion. Considering the efficiency of measurement, preferable stirring time was $8 \mathrm{~h}$.

Heat treatment and additives had effects on the chlorine ion content. Single heat treatment showed limited influence on the decrease of the chlorine ion content. Adding additives, especially the coal ash, led to obvious decrease of the chlorine ion content. With the increasing amount of coal ash, the chlorine ion content decreased gradually. The chlorine ion content was $0.078 \mathrm{~g} / \mathrm{g}(7.8 \%)$ when adding $10 \%$ coal ash.

\section{Acknowledgement}

In this paper, the research was sponsored by Science and Technology Bureau of Tangshan (Project No. 13130222A).

\section{References}

[1] W.EZEK, O.CELESTINE,Some basic geotechnical properties of expansive soil modified using pyroclastic dust, Engineering Geology, 107 (2009), 61-65.

[2] S.L.Sun, Q.H.Zheng, J.Tang, et al, Experimental research on expansive soil improved by soda residue,Rock and Soil Mechanics,6 (62012),1608-1612.

[3] J.J.Yang,W.Xie,L.Zhang, Study on Experimental Preparation of Cement Mortar Incorporating Fly Ash-soda Residue, Bulletin of the Chinese Ceramic Society, ,5 (2010),1211-1216.

[4] Y.Y.Li, S.W.Yan, J.Y.Zhang, et al. Engineering properties and microstructural features of the soda residue. Chinese Journal of Geotechnical Engineering, 1 (1999),101.

[5]R.K.Agarwal,S.V.Paralkar, A,K,Chatterjee, Chloride salts as reaction medium for low temperature clinkrisation-a probe into alinite technology. 8th International Congress Chemical Cement. 1986. 